\title{
GABAergic Neurons in the Central Region of the Spinal Cord: A Novel Substrate for Sympathetic Inhibition
}

\author{
Susan A. Deuchars, ${ }^{1}$ Carol J. Milligan, ${ }^{1}$ Ruth L. Stornetta, ${ }^{2}$ and Jim Deuchars ${ }^{1}$ \\ ${ }^{1}$ School of Biomedical Sciences, University of Leeds, Leeds LS2 9NQ, United Kingdom, and ${ }^{2}$ Department of Pharmacology, University of Virginia, \\ Charlottesville, Virginia 22908-0735
}

\begin{abstract}
Homeostatic maintenance of widespread functions is critically dependent on the activity of the sympathetic nervous system. This activity is generated by the CNS acting on the sole output cells in the spinal cord, sympathetic preganglionic neurons (SPNs). SPNs are subject to control from both supraspinal and spinal inputs that exert effects through activation of direct or indirect pathways. A high proportion of indirect control is attributable to activation of spinal interneurons in a number of locations. However, little is known about the different groups of interneurons with respect to their neurochemistry or function. In this study, we report on a novel group of GABAergic interneurons located in the spinal central autonomic area (CAA) that directly inhibit SPN activity. In situ hybridization studies demonstrated a group of neurons that contained mRNA for glutamic acid decarboxylase (GAD) ${ }_{65}$ and $\mathrm{GAD}_{67}$ within the CAA. Combining in situ hybridization with trans-synaptic labeling from the adrenal gland using pseudorabies virus identified presympathetic GABAergic neurons in the CAA. Electrical stimulation of the CAA elicited monosynaptic IPSPs in SPNs located laterally in the intermediolateral cell column. IPSPs were GABAergic, because they reversed at the chloride reversal potential and were blocked by bicuculline. Chemical activation of neurons in the CAA hyperpolarized SPNs, an effect that was also bicuculline sensitive. We conclude that the CAA contains GABAergic interneurons that impinge directly onto SPNs to inhibit their activity and suggest that these newly identified interneurons may play an essential role in the regulation of sympathetic activity and thus homeostasis.
\end{abstract}

Key words: sympathetic preganglionic; interneuron; cardiovascular; electrophysiology; in situ hybridization; bicuculline

\section{Introduction}

Sympathetic preganglionic neurons (SPNs) are a functionally heterogeneous group of neurons involved in regulating the heart, adrenal medulla, vascular smooth muscle, liver, kidney, and many other organs (Cabot, 1990). Influences on the activity of SPNs therefore play an important role in determining the normal function of many systems in the body. Such influences include descending and segmental neuronal pathways that set the level of ongoing activity and participate in mediating reflex changes in SPN activity (Gilbey and Spyer, 1993). A vast proportion of bulbospinal inputs directly innervate SPNs in the intermediolateral cell column (IML) (Anderson et al., 1989; Zagon and Smith, 1993; Pyner and Coote, 1998). However, viral trans-synaptic labeling studies have revealed many interneurons that are involved in sympathetic control in specific areas of the spinal cord, including the IML and laminas V and VII (Cabot et al., 1994; Joshi et al., 1995), and these are likely candidates for mediating indirect supraspinal control of SPN activity. Recently, putative presympathetic interneurons have also been located in the central autonomic area (CAA), dorsal and lateral to the central canal (Clarke

Received Sept. 9, 2004; revised Dec. 10, 2004; accepted Dec. 14, 2004.

We thank the British Heart Foundation (GrantPG/2001119 to S.A.D. and J.D.), the Wellcome Trust (Grant 067309/ Z/02/Z to J.D. and S.A.D.), and the National Heart, Lung, and Blood Institute (Grant HL28785 to R.L.S.) for their generous support. We also thank Brenda Frater for her skilled technical contribution.

Correspondence should be addressed to Dr. Susan A. Deuchars, School of Biomedical Sciences, Worsley Building, University of Leeds, Leeds LS2 9NQ, UK. E-mail: S.A.Deuchars@leeds.ac.uk.

D01:10.1523/JNEUROSCI.3740-04.2005

Copyright $\odot 2005$ Society for Neuroscience $\quad$ 0270-6474/05/251063-08\$15.00/0 et al., 1998; Tang et al., 2004), a region that receives input from vasomotor regions of the brain (Caverson et al., 1983; Bacon and Smith, 1993; Zagon and Smith, 1993). Interestingly, axons from the medial prefrontal cortex made asymmetric synapses onto small dendrites in the CAA, and stimulation of this cortical region causes hypotension (Bacon and Smith, 1993). Because hypotension is likely attributable to a reduction in SPN activity but the descending pathway is excitatory, this suggests that there are presympathetic inhibitory interneurons in the CAA.

A high proportion of ongoing inhibitory transmission onto SPNs in the spinal cord slice is glycinergic (Dun and Mo, 1989; Krupp and Feltz, 1993; Krupp et al., 1994; Spanswick et al., 1994). However, GABAergic terminals onto SPNs are preserved in spinalized animals (Llewellyn-Smith, 2002), and it is possible to record ongoing GABAergic IPSPs from SPNs in the spinal cord slice (S. A. Deuchars, unpublished observations), suggesting that GABAergic interneurons are preserved in this preparation.

In this study, we provide evidence that a group of GABAergic interneurons is located in the CAA of the spinal cord. Transneuronal labeling of presympathetic neurons combined with in situ hybridization demonstrates that at least a proportion of interneurons in this region are GABAergic. We therefore investigated the effects of electrical and chemical stimulation within this region on SPN activity.

\section{Materials and Methods}

In situ hybridization

In situ hybridization was performed using protocols that have been described in detail previously (Stornetta and Guyenet, 1999). Briefly, 
Wistar rats $(20-300 \mathrm{~g})$ were anesthetized with Sagatal $(60 \mathrm{mg} / \mathrm{kg}$, i.p.; Rhone Merieux, Harlow, Essex, UK) and perfused transcardially with 4\% paraformaldehyde (PFA). Coronal $30 \mu \mathrm{m}$ sections were cut at room temperature on a vibrating microtome (Leica, Milton Keynes, UK) and hybridized with single-stranded digoxigenin (DIG)-UTP-labeled (Roche Molecular Biochemicals, Welwyn Garden City, UK) sense (control) and antisense riboprobes transcribed from a $3.2 \mathrm{~kb}$ glutamic acid decarboxylase $(\mathrm{GAD})_{67}$ DNA template or from a $2.3 \mathrm{~kb} \mathrm{GAD}_{65}$ DNA template from plasmids kindly supplied and previously characterized by A. Tobin (The Brain Research Institute, University of California Los Angeles, Los Angeles, CA) (Wuenschell et al., 1986; Esclapez et al., 1993). Hybridized mRNA was localized by anti-DIG alkaline phosphataseconjugated antibody (1:1000; Roche Molecular Biochemicals) that was visualized colorimetrically with the alkaline phosphatase substrates nitroblue tetrazolium chloride and 5-bromo-4-chloro-3-indolyl phosphate diluted in Tris- $\mathrm{HCl} / \mathrm{MgCl}_{2}, \mathrm{pH} 9.5$, for $1-2 \mathrm{~h}$ at room temperature under intermittent microscopic observation to determine the optimal signal-to-noise ratio (i.e., no signal in motor neurons; strong signal in known GABAergic areas). The reaction was quenched with three $10 \mathrm{~min}$ rinses in $0.1 \mathrm{~m}$ Tris/1 mM EDTA, $\mathrm{pH}$ 8.5. The sections were air-dried, mounted in Aquamount, and viewed on a Nikon (Tokyo, Japan) E600 microscope.

\section{Trans-synaptic labeling}

Injection of pseudorabies virus. Thirty male Sprague Dawley rats (Taconic, Germantown, NY) were anesthetized with a mixture of ketamine (75 $\mathrm{mg} / \mathrm{kg})$, xylazine $(5 \mathrm{mg} / \mathrm{kg})$, and acepromazine $(1 \mathrm{mg} / \mathrm{kg})$ administered intramuscularly. All surgery was done using aseptic procedures. A $4 \mathrm{~cm}$ retroperitoneal incision was made dorsally over the kidney, and the adrenal gland was exposed. A glass micropipette (tip diameter, 30-50 $\mu \mathrm{m}$ ) was inserted $\sim 1 \mathrm{~mm}$ below the surface of the adrenal gland to target the adrenal cortex with the aid of a micromanipulator. One microliter of pseudorabies virus (PRV; Bartha strain BaBlu; generously supplied by Lynn Enquist, Princeton University, Princeton, NJ) at a concentration of $10^{8} \mathrm{pfu} / \mathrm{ml}$ was injected in approximate $100 \mathrm{nl}$ bursts over the course of $30-60$ s using a Picospritzer (General Valve Corporation, East Hanover, $\mathrm{NJ}$ ) connected to the glass micropipette. One minute elapsed between the end of the injection and withdrawal of the micropipette. Any backflow of virus was then immediately washed with physiological saline. Five rats used as controls received sham injections of $1 \mu \mathrm{l}$ of PRV applied to the surface of fat deposits located next to the adrenal gland without penetration of any tissue with the micropipette tip. The virus was left for $1 \mathrm{~min}$, the area was then washed with sterile saline, and the incision was sutured. Animals received an antibiotic (ampicillin, $125 \mathrm{mg} / \mathrm{kg}$, i.m.) and an analgesic (Ketorolac, $0.5 \mathrm{mg} / \mathrm{kg}$, s.c.). Animals recovered, were given an overdose of urethane intraperitoneally $12-96 \mathrm{~h}$ later, and were transcardially perfused with $500 \mathrm{U}$ of heparin sulfate followed by $100 \mathrm{ml}$ of $0.9 \%$ PBS, pH 7.4, and then by $500 \mathrm{ml}$ of $4 \%$ PFA in $0.1 \mathrm{M}$ phosphate buffer, $\mathrm{pH}$ 7.4. Brains and spinal cords were removed and postfixed in the same fixative for $24-72 \mathrm{~h}$ at $4^{\circ} \mathrm{C}$. Fifty-micrometer-thick sections of spinal cord were cut in the coronal plane with a vibrating microtome (Leica, Nussloch, Germany) and stored in a cryoprotectant solution (50\% sterile $100 \mathrm{~mm}$ sodium phosphate buffer, 30\% ethylene glycol, and 20\% RNasefree glycerol) at $-20^{\circ} \mathrm{C}$.

In situ hybridization. Sections were removed from cryoprotectant solution and rinsed in sterile saline, and in situ hybridization was performed as described above.

Immunohistochemistry. Immunohistochemical detection of PRV BaBlu was performed using a rabbit antibody against PRV (1:5000; supplied by Lynn Enquist). At the conclusion of the in situ hybridization $\mathrm{H}_{2} \mathrm{O}_{2}$ quenching step, sections were rinsed in $100 \mathrm{~mm}$ Tris buffered saline (TBS), $\mathrm{pH}$ 7.4. All solutions and rinses described hereafter used TBS. Sections were incubated free-floating for $60 \mathrm{~min}$ with goat anti-rabbit IgG-cyanine 3 (Cy3) (1:200; Jackson ImmunoResearch, West Grove, PA). Sections were then rinsed and mounted on slides and covered with VectaShield (Vector Laboratories, Burlingame, CA). Coverslips were affixed with nail polish.

Case selection. A preliminary study of the spinal cord examining segments from throughout the thoracic spinal cord was performed to ascer- tain whether SPNs were contaminated and to eliminate cases in which PRV may also have entered the CNS via motor neurons in addition to adrenal gland SPNs. Although great care was taken not to infect muscle tissue at the site of PRV injection, we found a few cases with infection of large ventral horn neurons presumed to be motor neurons. Similar observations were reported by Westerhaus and Loewy (1999) and, following their example, we excluded these cases from additional analysis because there are no known direct connections between motor neurons and SPNs and at the very early stage of infection, PRV-infected motor neurons could only have picked up the virus directly from a muscle. In our hands, intentional virus spills in the retroperitoneal cavity without penetration of the injection pipette into tissue never produced infection in the spinal cord, but in these experiments, the virus was quickly diluted by washes. We hypothesize that, in some rare cases, backflow of concentrated virus leaking slowly from the injected adrenal medulla onto a small region of nearby muscle may have led to contamination of motor neurons. Sections were examined under bright-field fluorescence and epifluorescence with a Leitz (Wetzlar, Germany) Ortholux II microscope. Photographs were taken with a 12 bit color CCD camera (CoolSnap; Roper Scientific, Tucson, AZ; resolution $1392 \times 1042$ pixels) and the resulting TIFF files were imported into Adobe Photoshop (version 7; Adobe Systems, Mountain View, CA). Output levels were adjusted to include all information containing pixels. Balance and contrast were adjusted to reflect true rendering as much as possible. No other "photo-retouching" was done. Figures were assembled and labeled within the Photoshop software.

\section{Electrophysiology}

Rats aged $10-15 \mathrm{~d}$ were anesthetized with urethane $(2 \mathrm{~g} / \mathrm{kg}$, i.p.). The upper and middle thoracic spinal cord was removed and sectioned (250 $\mu \mathrm{m}$ thick). Slices were then submerged in artificial CSF (aCSF) (in mм: $124 \mathrm{NaCl}, 26 \mathrm{NaHCO}_{3}, 3 \mathrm{KCl}, 2 \mathrm{MgSO}_{4}, 2.5 \mathrm{NaH}_{2} \mathrm{PO}_{4}, 2 \mathrm{CaCl}_{2}$, and 10 glucose), equilibrated with $95 \% \mathrm{O}_{2} / 5 \% \mathrm{CO}_{2}$, and superfused at a rate of $3-5 \mathrm{ml} / \mathrm{min}$ as described previously (Deuchars et al., 2001a,b; Brooke et al., 2004). SPNs within the IML were targeted for these experiments, identified both electrophysiologically and anatomically as described previously (Deuchars et al., 2001a,b; Brooke et al., 2004).

Whole-cell patch-clamp recordings were made in current-clamp mode using an Axopatch 1D (Axon Instruments, Foster City, CA), and the liquid junction potential was taken into account to calculate accurately the reversal potentials of IPSPs. Patch electrodes (tip diameter, 3 $\mu \mathrm{m}$; resistance, $4-6 \mathrm{M} \Omega$ ) were filled with (in mM): $110 \mathrm{~K}$-gluconate, 11 EGTA, $2 \mathrm{MgCl}_{2}, 0.1 \mathrm{CaCl}_{2}, 10$ HEPES, $2 \mathrm{Na}_{2} \mathrm{ATP}$, and $0.3 \mathrm{Na}_{2} \mathrm{GTP}, \mathrm{pH}$ $7.2,295 \mathrm{mOsm}$. Neurobiotin $(0.5 \%)$ was included in the patch solution and diffused into the neuron during recording.

The CAA and the lateral funiculus (LF) were stimulated with single pulses (above the threshold for response but ensuring that the response was submaximal) using bipolar stimulating electrodes and isolated stimulators (DS2A; Digitimer, Hertfordshire, UK). IPSPs were elicited at more depolarized potentials $(-20$ to $+10 \mathrm{mV})$, either in control conditions or in solution containing selective excitatory amino acid receptor antagonists.

For microinjection studies, single-barreled electrodes were pulled and broken back to a tip diameter of $10 \mu \mathrm{m}$. These were filled with $40 \mathrm{~mm}$ glutamate and placed below the surface of the cord in the CAA as before. Neurons were held at -20 to $0 \mathrm{mV}$ in control aCSF, and glutamate was ejected using a pneumatic picopump (one to four pulses of $10 \mathrm{~ms}$ duration; PV800; World Precision Instruments, Hertfordshire, UK) in the vicinity of the CAA. Because hyperpolarizations were observed with glutamate, it is likely that these responses are attributable to activation of excitatory amino acid receptors on the somata of inhibitory interneurons, which in turn inhibit SPNs in the IML.

Drugs were applied in the superfusing solution at a rate of $3-5 \mathrm{ml} / \mathrm{min}$, and the concentration given is the final concentration in the bath. The following drugs were used: bicuculline, $\mathrm{a} \mathrm{GABA}_{\mathrm{A}}$ antagonist, and strychnine, a glycinergic antagonist (Sigma/RBI, Poole, Dorset, UK). Excitatory amino acid receptors were blocked by either the nonselective antagonist kynurenic acid or a combination of the non-NMDA antagonist 1,2,3,4-tetrahydro-6-nitro-2,3-dioxobenzo[f] quinoxaline-7- 


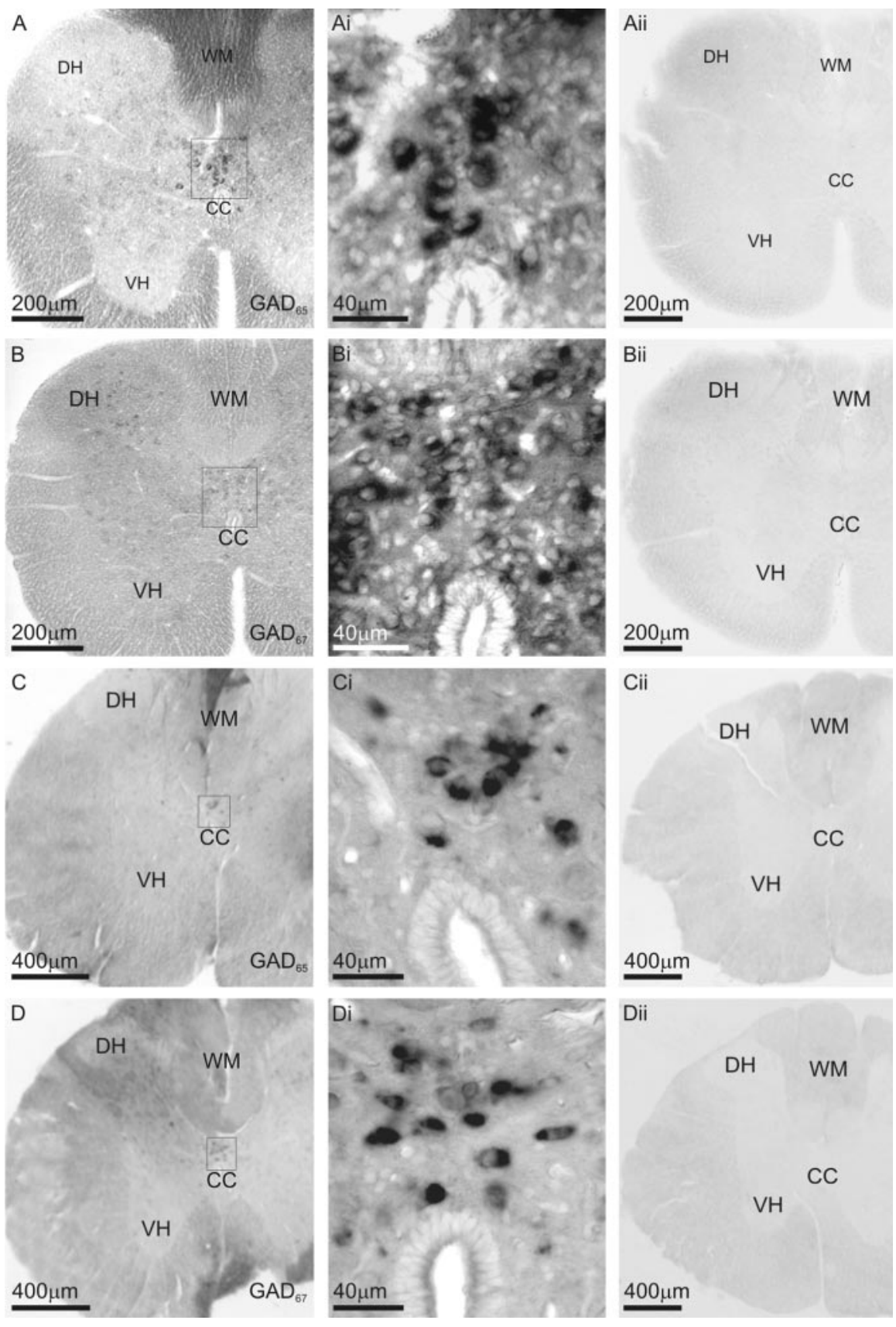

Figure 1. In situ hybridization reveals the presence of $\mathrm{GAD}_{65}$ and $\mathrm{GAD}_{67} \mathrm{mRNA}$ in adult and $\mathrm{P} 12$ rat spinal cord. $A-D$, Sections have been hybridized with antisense DIG-labeled riboprobes for either $\mathrm{GAD}_{65}$ or $\mathrm{GAD}_{67}$ and visualized with alkaline phosphatase reaction product. $A$, Section of $\mathrm{P} 12$ spinal cord indicating the presence of $\mathrm{GAD}_{65} \mathrm{mRNA}$. Ai, Larger magnification of the boxed area in $A$ indicating $G_{A D}$ mRNA highly expressed in a compact group of neurons dorsal to the central canal. $B, G A D_{67} m R N A$ in $P 12$ spinal cord. Bi, Larger magnification of the boxed area in $B$ showing labeled neurons dorsal to the central canal. $C, G_{65} m R N A$ in adult rat spinal cord. $C i$, Larger magnification of the boxed area in C indicating a compact group of labeled neurons dorsal to the central canal. $D, G A D_{67}$ mRNA in adult rat spinal cord. Di, Larger magnification of the boxed area in D indicating a group of labeled neurons dorsal to the central canal. Aii-Dii, Sections of spinal cord devoid of signal after hybridization with sense (control) DIG-labeled riboprobe for $\mathrm{GAD}_{65}$ (Aii, Cii) and $\mathrm{GAD}_{67}$ (Bii, Dii).

sulfonamide disodium (NBQX) and the NMDA receptor antagonist $\mathrm{D}(-)$-2-amino-5-phosphopentanoic acid (AP-5). Chemical stimulation was obtained using glutamate dissolved in saline or aCSF. All drugs were obtained from Tocris Cookson (Bristol, UK) and dissolved in water unless otherwise stated.

\section{Data analysis}

SPNs were identified electrophysiologically as described previously (Deuchars et al., 2001a,b; Brooke et al., 2004). IPSP amplitudes were measured as the peak changes from the holding potentials, averaged over 10 consecutive sweeps for control and drug responses, and are given as the mean \pm SEM. The effects of the drugs were tested statistically using the paired Student's $t$ test, and differences were considered significant when $p<0.05$.

\section{Results}

In situ hybridization reveals GABAergic neurons in the CAA of the spinal cord

GABAergic neurons were identified by expression of $\mathrm{GAD}_{65}$ and $\mathrm{GAD}_{67}$ mRNA in adult and postnatal day 12 (P12) rat spinal cord sections, using in situ hybridization with DIG-labeled antisense riboprobes (Fig. 1).

Dense labeling indicates that $\mathrm{GAD}_{65}$ and $\mathrm{GAD}_{67}$ mRNA is highly enriched in the cytoplasm of a compact group of neurons dorsal to the central canal of the spinal cord. Less-intense labeling indicates that cells of the dorsal horn express lower levels of mRNA for $\mathrm{GAD}_{65}$ or $\mathrm{GAD}_{67}$ compared with those of the CAA. No labeling was observed in sections hybridized with $\mathrm{GAD}_{65}$ and $\mathrm{GAD}_{67}$ sense DIG-labeled riboprobes (Fig. 1Aii-Dii). Although $\mathrm{GAD}_{67}$ is coexpressed with vesicular glutamate transporter 2 in some neurons (e.g., the preoptic area) (Ottem et al., 2004), this is an unusual occurrence not reported in the spinal cord. Furthermore, the location of GAD-expressing neurons correlates with the source of GABAergic inhibition in SPNs revealed here (see below).

\section{Trans-synaptic tracing reveals presympathetic neurons that are $\mathrm{GAD}_{67}$ mRNA positive}

\section{Time course and appearance of $P R V$ -}

infected cells

PRV-infected neurons were first observed in the IML, the intercalated nucleus, and the CAA of the thoracic spinal cord 24-48 $\mathrm{h}$ after injection. The distribution of cells in the thoracic spinal cord from the adrenal injections closely matched that seen by Strack et al. (1988, 1989) in similar experiments with a peak concentration in thoracic segments 6-9. No infected cells were observed in cervical cord. The PRV immunoreactivity had a characteristic granular appearance in cell nuclei with a more uniform appearance in the cell cytoplasm and primary dendrites. In 4 of the 30 cases, large infected neurons presumed to be somatic motor neurons were observed in the ventral horn, and these cases were excluded from additional analysis (see Materials and Methods). At 84-96 h after infection (four cases), an increasing number of neurons were observed in the spinal cord, and at this time point it was not possible to detect the host mRNAs for $\mathrm{GAD}_{67}$ in PRV-infected cells. Eight cases from the $72 \mathrm{~h}$ time point where detection of $\mathrm{GAD}_{67}$ mRNA in PRV-infected neurons was 

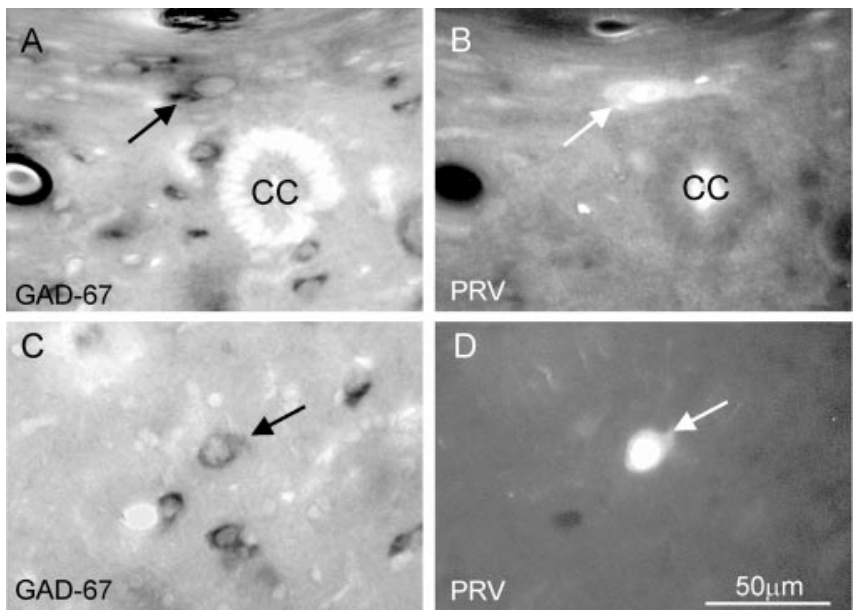

Figure 2. Distribution and appearance of $G_{A D}$ mRNA-containing cells infected with PRV. $A, C, G A D_{67}$ mRNA labeled with a DIG riboprobe (bright field). $B, D$, PRV labeled with antibody visualized with $\mathrm{Cy} 3$ (fluorescence). The arrows point to double-labeled neurons. The example shown in $A$ and $B$ is dorsal to the central canal. The example shown in $C$ and $D$ is located lateral to the central canal. $c c$, Central canal. Scale bar: (in D) $A-D, 50 \mu \mathrm{m}$.

still possible were chosen for the mapping and photographic examples we report.

Cells containing both PRV and $\mathrm{GAD}_{67}$ mRNA were rarely seen (approximately one to five successfully double-labeled cells per 10 coronal thoracic cord sections) (Fig. 2), likely because of the difficulty of detecting mRNA in virally infected cells (Oroskar and Read, 1989; Stornetta et al., 2004). The neurons in which both $\mathrm{GAD}_{67}$ mRNA and PRV could be detected were at an early stage of viral infection, because PRV immunoreactivity was present primarily in the nucleus and little or none was detectable in the soma or primary dendrites. Detecting the host mRNAs in virally infected cells is limited to early stages of viral contamination, because viruses repress host gene transcription (Gaynor et al., 1985) and degrade host mRNAs (Oroskar and Read, 1989; Stornetta et al., 2004). Figure 2 illustrates examples of neurons from two separate cases. The neurons were found in layers 5, 7, and 10 in thoracic cord segments $6-10$, with some presympathetic GABAergic neurons from four of the seven cases located in the CAA.

\section{Stimulation within the CAA elicits monosynaptic IPSPs}

Recordings were made from SPNs identified according to their electrophysiological characteristics and their morphology as described in detail previously (Deuchars et al., 2001a,b). Briefly, SPNs were distinguished from interneurons by the voltage responses to hyperpolarizing and depolarizing current pulses. The shape of the action potential was also different; SPNs exhibited a characteristic deflection of the repolarizing phase that prolonged action potential duration and a large afterhyperpolarization. At the end of the recording, the labeled neuron was verified as an SPN by the distinctive morphology.

Electrical stimulation within the CAA region containing GABAergic neurons elicited IPSPs in all of the SPNs tested with constant latencies [mean latency, $4.9 \pm 0.3 \mathrm{~ms}$ (mean $\pm \mathrm{SEM}$ ); $n=27$. These IPSPs were robust and could follow stimulation frequencies of up to $100 \mathrm{~Hz}$, which indicated that they were monosynaptic in nature. Additional support may be deduced from the fact that IPSPs were not reduced in amplitude by application of the nonselective excitatory amino acid antagonist kynurenic acid ( $1 \mathrm{mM}$ ) or NBQX and AP-5 (4.3 \pm 0.9 to $5.2 \pm 1.0$;

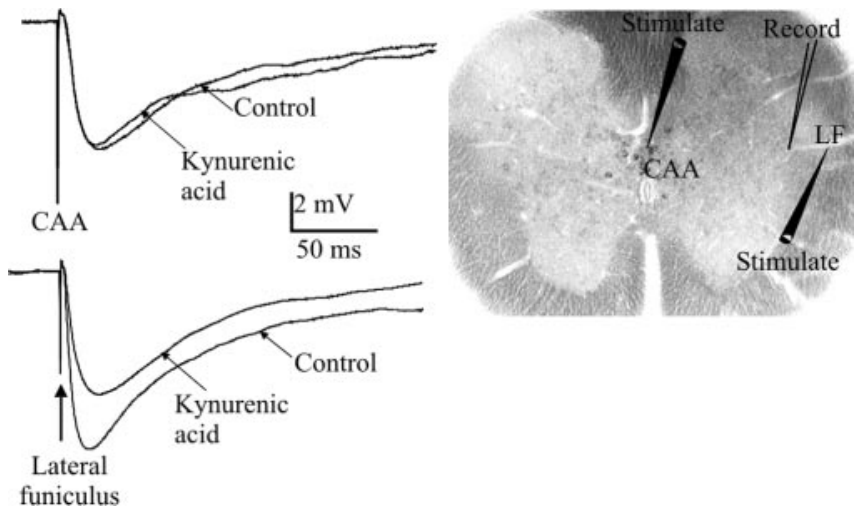

Figure 3. Stimulation of the CAA elicits monosynaptic IPSPs in SPNs. Electrical stimulation of either the CAA (top) or the lateral funiculus (bottom) elicited IPSPs in an SPN held at $-10 \mathrm{mV}$. CAA-evoked IPSPs were not affected by kynurenic acid in this SPN, whereas the LF-evoked IPSP was reduced in amplitude (averages of 10 sweeps). The areas stimulated are shown on the spinal cord slice, as is the region of recorded SPNs.

$n=8 ; p=$ NS) (Fig. 3), antagonists that have been shown previously to block polysynaptic IPSPs elicited by stimulation of bulbospinal pathways with axons that descend into the lateral funiculus (Deuchars et al., 1997). Stimulation of the LF also elicited IPSPs, and the properties of these were compared with those of central region-evoked IPSPs. LF-evoked IPSPs were also not significantly affected by application of kynurenic acid ( $6.3 \pm 2.3$ to $5.8 \pm 1.6 \mathrm{mV} ; n=8 ; p=\mathrm{NS}$ ).

The latencies to onset of the IPSPs elicited by CAA or LF stimulation were compared. IPSPs elicited by CAA stimulation had an onset latency of $4.8 \pm 0.4 \mathrm{~ms}$, which was significantly greater than that of LF-evoked IPSPs $(3.6 \pm 0.2 \mathrm{~ms} ; n=19)$. This may be attributable to the difference in the lengths of the pathways that are activated, because the lateral funiculus lies adjacent to the IML (which makes it difficult to measure the exact length of the pathway) and is therefore likely to be significantly shorter than the pathway activated in the central region.

To eliminate the possibility that IPSPs elicited by stimulation of the CAA may be caused by activation of fibers of passage from inputs onto SPNs that descend in the white matter dorsal to the CAA, electrodes were moved to this region. Stimulating in the white matter just dorsal to the central region (which may contain descending axons from the rostral ventrolateral medulla) (Pyner and Coote, 1998), the medial prefrontal area of the cortex (Bacon and Smith, 1993), and the paraventricular nucleus of the hypothalamus (Ranson et al., 1998) in the presence of kynurenic acid did not elicit IPSPs on all four occasions tested, although it was still possible to elicit an IPSP by stimulating in the LF (Fig. 4A). Stimulation in the contralateral IML/LF also did not elicit IPSPs, although IPSPs could still be elicited by stimulation of the CAA (Fig. $4 B$ ), which rules out the possibility that the IPSPs elicited by CAA stimulation were caused by activation of contralateral descending pathways that cross in this region of the gray matter.

IPSPs elicited by CAA stimulation reversed at the chloride equilibrium potential and were antagonized by bicuculline The reversal potential of the IPSPs elicited by CAA stimulation was calculated, and the average reversal potential was $-88.8 \pm 4$ $\mathrm{mV}(n=5)$ (Fig. 5), which is close to the equilibrium potential for chloride with the solutions used $(-88 \mathrm{mV})$. These IPSPs were subsequently also antagonized by bicuculline, showing that they were GABAergic in nature.

The effects of bath application of bicuculline on IPSPs elicited 
A
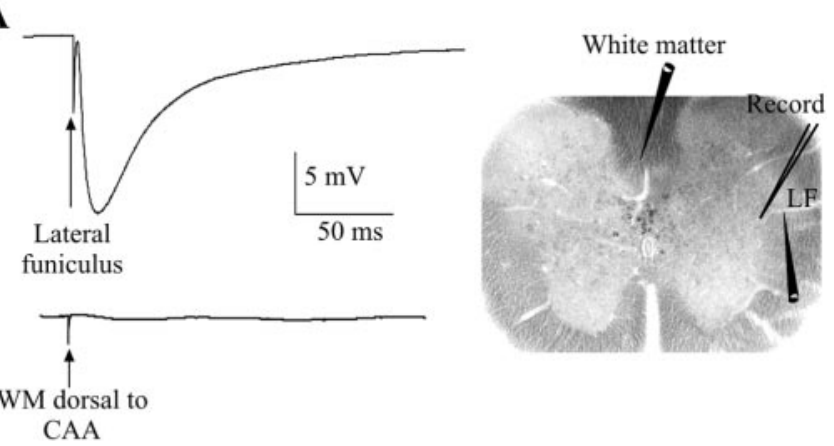

B
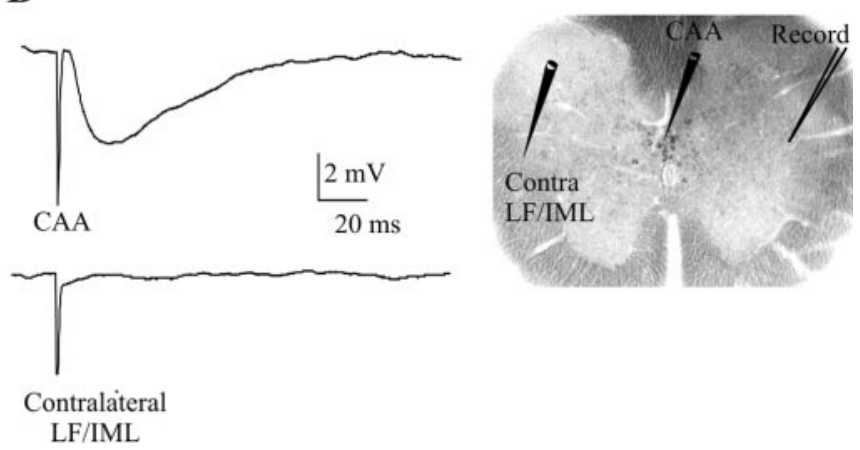

Figure 4. IPSPs are not elicited by stimulation outside of the CAA. A, Stimulation within the white matter dorsal to the CAA in the presence of kynurenic acid did not elicit an IPSP (bottom trace), although LF stimulation did still elicit IPSPs in the same SPN (top trace). B, Stimulation of the contralateral IML/LF region did not elicit IPSPs (bottom trace), although CAA stimulation did still yield a response (top trace). Averages of 10 consecutive sweeps are shown. SPNs were held at $-10 \mathrm{mV}$.

\section{A}
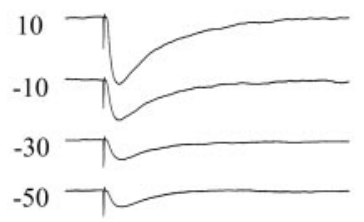

$-90 \longrightarrow$

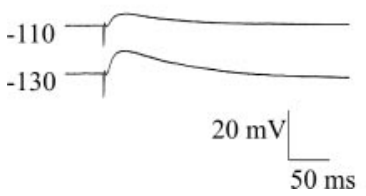

Figure 5. CAA IPSPs reverse at the equilibrium potential for chloride. $A$, IPSPs elicited at different holding potentials decreased in amplitude as the membrane was hyperpolarized and were positive-going at $-90 \mathrm{mV}$. These recordings were made in the presence of NBQX (10 $\mu \mathrm{m})$ and AP-5 $(50 \mu \mathrm{M}) . B$, Graph of IPSP amplitude against holding potential. The line of best fit gives a reversal potential of $-86.8 \mathrm{mV}$.

by both CAA and LF stimulation were tested. Bicuculline (10 $\mu \mathrm{M})$ antagonized IPSPs elicited by CAA stimulation, and the amplitude was significantly decreased from $7.1 \pm 0.9$ to $0.9 \pm 0.1 \mathrm{mV}$ $(n=26)$ (Fig. 6A,C), a decrease of $87 \%$. Applications of strychnine in the presence of bicuculline further reduced the IPSP to $0.3 \pm 0.1 \mathrm{mV}$, but this was not a significant change. On four occasions, strychnine was applied first and had no significant effect on IPSP amplitude, with the IPSP remaining at $94.6 \pm 3 \%$
A
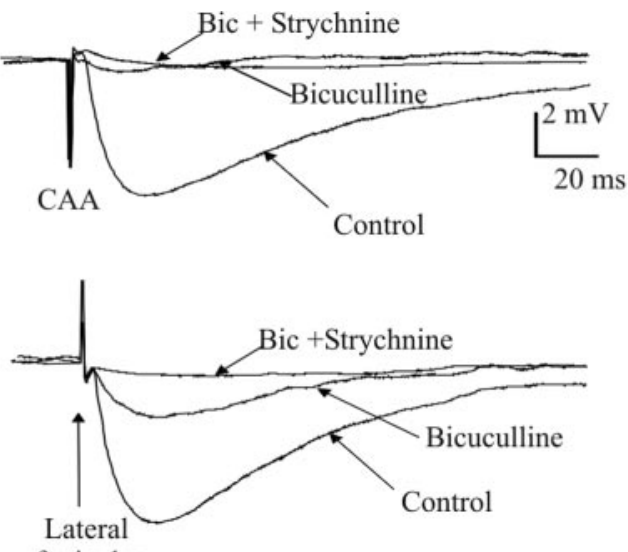

funiculus

B

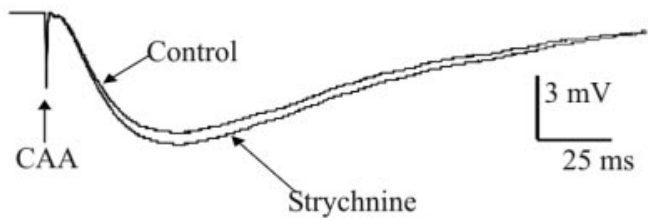

C

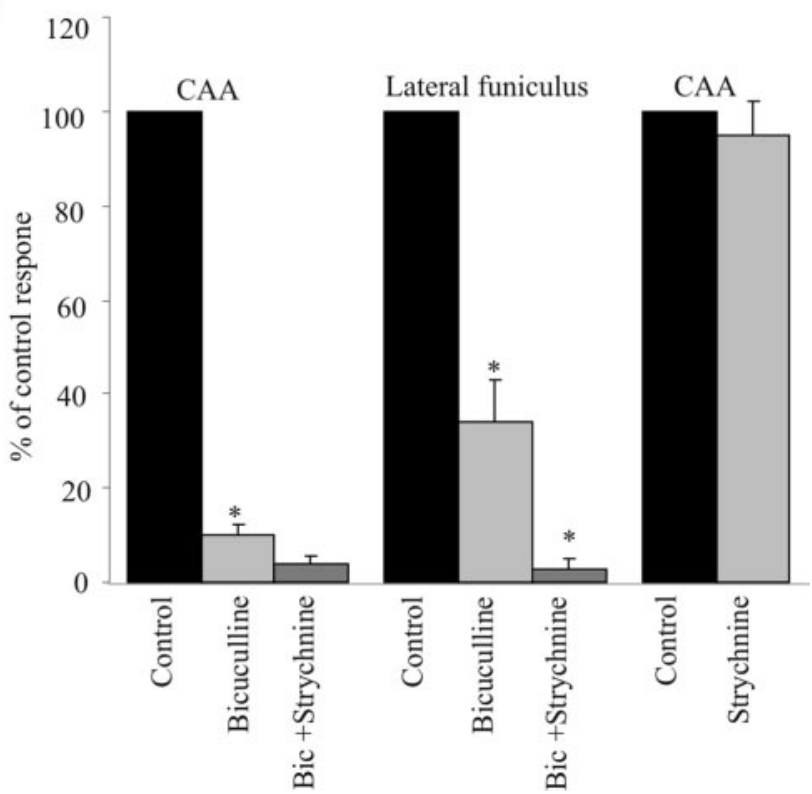

Figure 6. CAA IPSPs are GABAergic in nature. A, Stimulation within the CAA or LF elicited IPSPs in the presence of kynurenic acid (marked as control). Bicuculline $(5 \mu \mathrm{M}$ ) almost abolished the CAA-evoked response, and strychnine had little additional effect. In contrast, bicuculline reduced the amplitude of the LF-evoked IPSP, but strychnine together with bicuculline then abolished the remaining IPSP. B, CAA IPSPS were not significantly reduced by strychnine alone. All traces are averages of 10 consecutive sweeps. SPNs were held at $-10 \mathrm{mV}$. C, Pooled data showing that CAA-evoked IPSPs are GABAergic (blocked by bicuculline) and the more complex pharmacology of IPSPs elicited by LF stimulation.

of control values (Fig. $6 B, C$ ). In contrast, IPSPs elicited by LF stimulation were only partially, although significantly, antagonized by bicuculline ( $7.9 \pm 1.4$ to $2.2 \pm 0.5 \mathrm{mV} ; n=15$ ) (Fig. $6 \mathrm{~A}, \mathrm{C}$ ), and the remaining IPSP was further reduced by strychnine to $0.35 \pm 0.1 \mathrm{mV}$ (a significant change from the amplitude in bicuculline), suggesting that a greater component of these IPSPs was glycinergic. 
A

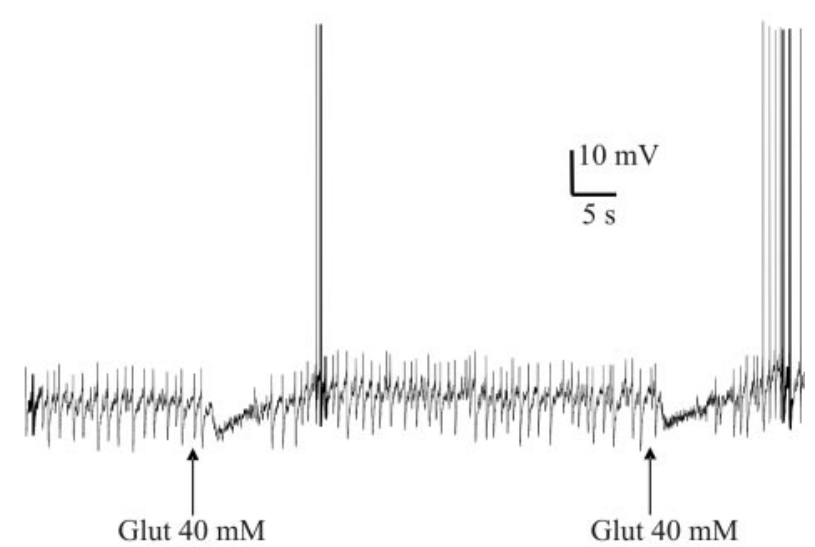

B

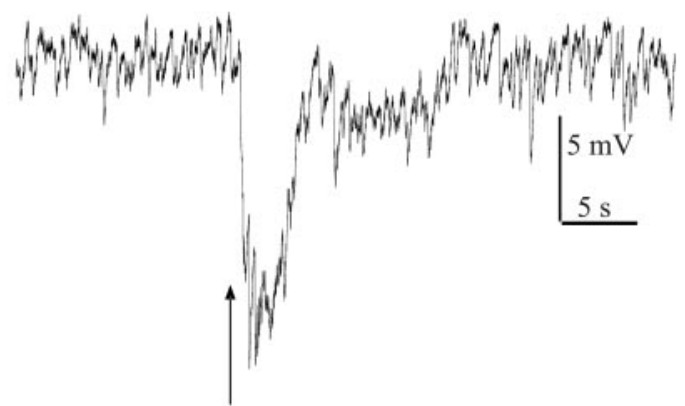

Glut $40 \mathrm{mM}$

In bicuculline, $10 \mu \mathrm{M}$

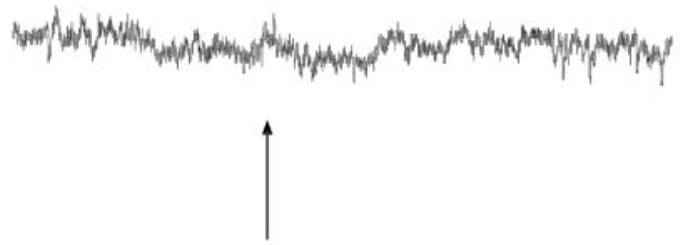

Glut $40 \mathrm{mM}$

Figure 7. Glutamate microinjections in the CAA hyperpolarize SPNs, and these effects are antagonized by bicuculline. $A$, Repeated microinjections of glutamate into the CAA caused reproducible hyperpolarizations in SPNs in the IML. In this cell, spikelets were also observed that are likely to be attributable to action potentials in an electrically coupled SPN. These spikelets were also reduced during glutamate application; this effect is not solely attributable to hyperpolarizing the membrane, because manual hyperpolarization to this level was not sufficient to reduce the frequency of spikelets in this cell. This indicated that the coupled SPN was also inhibited by glutamate microinjection. B, Glutamate microinjection in the CAA hyperpolarized this SPN in the IML. Bicuculline $(10 \mu \mathrm{M})$ antagonized this hyperpolarization.

\section{Chemical stimulation within the CAA elicits hyperpolarizations in SPNs in the IML}

Because electrical stimulation may activate both cell bodies and fibers of passage, we sought to determine the effects of microinjections of glutamate into the CAA to selectively activate cell bodies. Neurons were held at -20 to $0 \mathrm{mV}$, and microinjections of 40 mM glutamate elicited hyperpolarizations with a mean amplitude of $7.3 \pm 0.9 \mathrm{mV}(n=11)$. The onset of this effect was almost immediate and lasted for up to $45 \mathrm{~s}$. The effect was fully reproducible with hyperpolarizations of similar amplitude elicited on reapplication of glutamate (Fig. $7 A$ ). In an additional three SPNs in which no obvious hyperpolarization was observed, glutamate elicited decreases in ongoing activity. This activity was in the form of spontaneous depolarizations, which are likely to be truncated action potentials from electrically coupled SPNs similar to those observed on numerous occasions by others (Logan et al., 1996; Nolan et al., 1999). These spikelets reduced in frequency with hyperpolarization of the neuron, suggesting that the coupled neuron is also hyperpolarized because of passage of current through the gap junctions. In these neurons, it was possible to see a decrease in the frequency of spikelets with microinjection of glutamate even in the absence of any significant hyperpolarization of the recorded neuron. This suggests that the coupled neuron may be hyperpolarized by microinjection of glutamate.

On four occasions after robust hyperpolarizations with glutamate, bicuculline was bath applied onto the neuron before repeating the glutamate microinjection into the CAA. This significantly reduced the amplitude of hyperpolarization from $9.2 \pm 2.0$ to $1.2 \pm 0.9 \mathrm{mV}$, a decrease of $92 \%(n=4)$ (Fig. $7 B)$, suggesting that the hyperpolarizations were caused by activation of inhibitory GABAergic neurons in the vicinity of the CAA.

\section{Discussion}

In this study, we have identified a group of GABAergic neurons in a region just dorsal and lateral to the central canal known as the CAA. Trans-synaptic tracing with PRV combined with in situ hybridization revealed that some of the trans-synaptically labeled presympathetic neurons in the CAA contained mRNA encoding for $\mathrm{GAD}_{67}$, an enzyme involved in the synthesis of GABA in the CNS. Stimulation of the region containing these neurons elicited monosynaptic IPSPs in SPNs that were antagonized by bicuculline, indicating that they were mediated by GABA acting at $\mathrm{GABA}_{\mathrm{A}}$ receptors. Microinjections of glutamate into the CAA, which will activate cell bodies, elicited hyperpolarizations that were also blocked by bicuculline, consistent with the idea that activation of GABAergic neurons here inhibited SPNs. Together, these results indicate that a novel cluster of GABAergic presympathetic interneurons is located in the CAA, thus suggesting a role for these interneurons in mediating inhibitory control of SPNs.

\section{Are trans-synaptically labeled GABAergic neurons in the CAA presympathetic?}

Our evidence that the infected GABAergic neurons seen in the spinal cord were indeed second-order neurons (i.e., projected directly to the SPNs) relied on using lightly infected cases chosen at the earliest time point of infection beyond the SPNs (e.g., $72 \mathrm{~h}$ in the current study). This has been shown previously to maximize the odds of properly identifying second-order (presympathetic) neurons (Stornetta et al., 2004). The cases chosen were also analyzed for brainstem presympathetic neurons. The distribution of infected neurons in the brainstem of these same cases supports the conclusion that the interneurons in the spinal cord are second-order neurons rather than third-order neurons (Stornetta et al., 2004).

\section{Evidence for the involvement of GABAergic interneurons in sympathetic control}

To date, research into the ongoing inhibitory synaptic activity has indicated that the majority of ongoing activity in the reduced spinal cord slice is glycinergic in nature. Ongoing IPSPs were blocked by strychnine but not bicuculline (Dun and Mo, 1989; Krupp and Feltz, 1993; Krupp et al., 1994, 1997; Spanswick et al., 1994). This suggests that in this reduced preparation, glycinergic neurons are spontaneously active, causing ongoing inhibition of SPNs. However, although complete spinal transection of rats decreased the proportion of GABAergic boutons onto SPNs signif- 
icantly, $\sim 40 \%$ of somatic and $80 \%$ of dendritic GABAergic inputs remained (Llewellyn-Smith, 2002). Although a proportion of this input may be attributable to intersegmental GABAergic neurons because the cord was transected at the fourth thoracic level and SPNs were examined at the eighth thoracic level, the possibility of GABAergic interneurons in the vicinity of SPNs is a strong possibility. Our evidence, both anatomical and electrophysiological, supports this theory, because there are high numbers of interneurons in the spinal cord slice that contain mRNA for $\mathrm{GAD}_{65}$ and $\mathrm{GAD}_{67}$. Moreover, some neurons in the CAA that were trans-synaptically labeled after injection of PRV in the adrenal gland were also double labeled for $\mathrm{GAD}_{67}$, providing additional evidence that these GABAergic interneurons impinge onto SPNs. Chemical activation of this region elicited hyperpolarizations that were blocked by bicuculline, indicating that activation of these neurons can affect the level of activity of SPNs. The fact that these GABAergic interneurons appear to be mainly silent in the spinal cord slice may reflect their role in mediating descending inhibitory influences onto SPNs that are lost when the slice is prepared. These interneurons may be crucial in the maintenance of normal cardiovascular variables and restoration of such variables during hypertensive episodes but may play a less significant part in generating synaptic inputs during normotension.

\section{Functional significance}

Strong evidence exists for a role of these interneurons in mediating descending inhibitory influences on SPNs. Injections of glutamate into an area of the medial prefrontal cortex produced decreases in blood pressure of $\sim 15 \mathrm{mmHg}$ (Bacon and Smith, 1993). Tracers injected into this site labeled a descending pathway that directly innervated neurons in the CAA of the spinal cord corresponding to the region of GABAergic neurons in our study. Bacon and Smith (1993) speculated that because this region contained few SPNs, the depressor effects are likely to be attributable to activation of inhibitory interneurons, which in turn influence the activity of SPNs. Our study provides a possible substrate for this depressor effect, and thus these interneurons may be crucial in mediating supraspinal control of sympathetic activity. Additional evidence of a functional role for these GABAergic interneurons comes from direct extracellular recordings from interneurons in this region that displayed decreases in activity in response to occlusion of the common carotid artery (McCall et al., 1977). These neurons were activated by stimulating in the depressor region of the nucleus of the tractus solitarius, and 10 of these neurons had activity correlated with electrocardiogram activity. McCall et al. (1977) hypothesized that these interneurons directly inhibited SPNs in the IML but had no firm evidence to support this. Our results provide evidence for the existence of such a group of interneurons

\section{A role for synchronization of sympathetic activity?}

Numerous studies have revealed four distinct groups of SPNs located within the IML (majority), the intermediomedial spinal cord (IMM), the intercalated nucleus, and the nucleus intermediolateralis pars funicularis. The interneurons described here in the CAA lie in close proximity to the SPNs in the IMM and could be considered to innervate these neurons. Because our data here demonstrate that activation of these interneurons also directly inhibits SPNs in the IML, these neurons may play a role in synchronizing the level of excitability in two subsets of SPNs.

In summary, we have shown through in situ hybridization, viral tracing, and electrophysiology that there is a distinct group of GABAergic interneurons located dorsal to the central canal that are involved in sympathetic function. Electrical or chemical stimulation of these interneurons inhibits SPNs in the IML through activation of GABA receptors. These interneurons may play a crucial role in mediating the level of supraspinal control of sympathetic outflow at the level of the spinal cord.

\section{References}

Anderson CR, McLachlan EM, Srb-Christie O (1989) Distribution of sympathetic preganglionic neurons and monoaminergic nerve terminals in the spinal cord of the rat. J Comp Neurol 283:269-284.

Bacon SJ, Smith AD (1993) A monosynaptic pathway from an identified vasomotor centre in the medial prefrontal cortex to an autonomic area in the thoracic spinal cord. Neuroscience 54:719-728.

Brooke RE, Deuchars J, Deuchars SA (2004) Input-specific modulation of neurotransmitter release in the lateral horn of the spinal cord via adenosine receptors. J Neurosci 24:127-137.

Cabot JB (1990) Sympathetic preganglionic neurons: cytoarchitecture, ultrastructure, and biophysical properties. In: Central regulation of autonomic functions (Loewy AD, Spyer KM, eds), pp 22-34. New York: Oxford UP.

Cabot JB, Alessi V, Carroll J, Ligorio M (1994) Spinal cord lamina V and lamina VII interneuronal projections to sympathetic preganglionic neurons. J Comp Neurol 347:515-530.

Caverson MM, Ciriello J, Calaresu FR (1983) Cardiovascular afferent inputs to neurons in the ventrolateral medulla projecting directly to the central autonomic area of the thoracic cord in the cat. Brain Res 274:354-358.

Clarke HA, Dekaban GA, Weaver LC (1998) Identification of lamina V and VII interneurons presynaptic to adrenal sympathetic preganglionic neurons in rats using a recombinant herpes simplex virus type 1 . Neuroscience 85:863-872.

Deuchars SA, Spyer KM, Gilbey MP (1997) Stimulation within the rostral ventrolateral medulla can evoke monosynaptic GABAergic IPSPs in sympathetic preganglionic neurons in vitro. J Neurophysiol 77:229-235.

Deuchars SA, Brooke RE, Deuchars J (2001a) Adenosine A1 receptors reduce release from excitatory but not inhibitory synaptic inputs onto lateral horn neurons. J Neurosci 21:6308-6320.

Deuchars SA, Brooke RE, Frater B, Deuchars J (2001b) Properties of interneurones in the intermediolateral cell column of the rat spinal cord: role of the potassium channel subunit Kv3.1. Neuroscience 106:433-446.

Dun NJ, Mo N (1989) Inhibitory postsynaptic potentials in neonatal rat sympathetic preganglionic neurones in vitro. J Physiol (Lond) 410:267-281.

Esclapez M, Tillakaratne NJ, Tobin AJ, Houser CR (1993) Comparative localization of mRNAs encoding two forms of glutamic acid decarboxylase with nonradioactive in situ hybridization methods. J Comp Neurol 331:339-362.

Gaynor RB, Feldman LT, Berk AJ (1985) Transcription of class III genes activated by viral immediate early proteins. Science 230:447-450.

Gilbey MP, Spyer KM (1993) Essential organization of the sympathetic nervous system. Baillieres Clin Endocrinol Metab 7:259-278.

Joshi S, Levatte MA, Dekaban GA, Weaver LC (1995) Identification of spinal interneurons antecedent to adrenal sympathetic preganglionic neurons using trans-synaptic transport of herpes simplex virus type 1 . Neuroscience 65:893-903.

Krupp J, Feltz P (1993) Synaptic- and agonist-induced chloride currents in neonatal rat sympathetic preganglionic neurones in vitro. J Physiol (Lond) 471:729-748.

Krupp J, Larmet Y, Feltz P (1994) Postnatal change of glycinergic IPSC decay in sympathetic preganglionic neurons. NeuroReport 5:2437-2440.

Krupp J, Bordey A, Feltz P (1997) Electrophysiological evidence for multiple glycinergic inputs to neonatal rat sympathetic preganglionic neurons in vitro. Eur J Neurosci 9:1711-1719.

Llewellyn-Smith IJ (2002) GABA in the control of sympathetic preganglionic neurons. Clin Exp Pharmacol Physiol 29:507-513.

Logan SD, Pickering AE, Gibson IC, Nolan MF, Spanswick D (1996) Electrotonic coupling between rat sympathetic preganglionic neurones in vitro. J Physiol (Lond) 495:491-502.

McCall RB, Gebber GL, Barman SM (1977) Spinal interneurons in the baroreceptor reflex arc. Am J Physiol 232:H657-H665.

Nolan MF, Logan SD, Spanswick D (1999) Electrophysiological properties of electrical synapses between rat sympathetic preganglionic neurones in vitro. J Physiol (Lond) 519:753-764. 
Oroskar AA, Read GS (1989) Control of mRNA stability by the virion host shutoff function of herpes simplex virus. J Virol 63:1897-1906.

Ottem EN, Godwin JG, Krishnan S, Petersen SL (2004) Dual-phenotype GABA/glutamate neurons in adult preoptic area: sexual dimorphism and function. J Neurosci 24:8097-8105.

Pyner S, Coote JH (1998) Rostroventrolateral medulla neurons preferentially project to target-specified sympathetic preganglionic neurons. Neuroscience 83:617-631.

Ranson RN, Motawei K, Pyner S, Coote JH (1998) The paraventricular nucleus of the hypothalamus sends efferents to the spinal cord of the rat that closely appose sympathetic preganglionic neurones projecting to the stellate ganglion. Exp Brain Res 120:164-172.

Spanswick D, Pickering AE, Gibson IC, Logan SD (1994) Inhibition of sympathetic preganglionic neurons by spinal glycinergic interneurons. Neuroscience 62:205-216.

Stornetta RL, Guyenet PG (1999) Distribution of glutamic acid decarboxylase mRNA-containing neurons in rat medulla projecting to thoracic spinal cord in relation to monoaminergic brainstem neurons. J Comp Neurol 407:367-380.

Stornetta RL, McQuiston TJ, Guyenet PG (2004) GABAergic and glyciner- gic presympathetic neurons of rat medulla oblongata identified by retrograde transport of pseudorabies virus and in situ hybridization. J Comp Neurol 479:257-270.

Strack AM, Sawyer WB, Marubio LM, Loewy AD (1988) Spinal origin of sympathetic preganglionic neurons in the rat. Brain Res 455:187-191.

Strack AM, Sawyer WB, Platt KB, Loewy AD (1989) CNS cell groups regulating the sympathetic outflow to adrenal gland as revealed by transneuronal cell body labeling with pseudorabies virus. Brain Res 491:274-296.

Tang X, Neckel ND, Schramm LP (2004) Spinal interneurons infected by renal injection of pseudorabies virus in the rat. Brain Res 1004:1-7.

Westerhaus MJ, Loewy AD (1999) Sympathetic-related neurons in the preoptic region of the rat identified by viral transneuronal labeling. J Comp Neurol 414:361-378.

Wuenschell CW, Fisher RS, Kaufman DL, Tobin AJ (1986) In situ hybridization to localize mRNA encoding the neurotransmitter synthetic enzyme glutamate decarboxylase in mouse cerebellum. Proc Natl Acad Sci USA 83:6193-6197.

Zagon A, Smith AD (1993) Monosynaptic projections from the rostral ventrolateral medulla oblongata to identified sympathetic preganglionic neurons. Neuroscience 54:729-743. 